\title{
Correlation of the Protein to Creatinine Ratio with the 24-hour Urine Protein Level in Pregnancy Complicated by Hypertension
}

\author{
Hanumant V Nipanal ${ }^{1}$, Dilip Kumar Maurry ${ }^{2}$, Susmitha S Reddy ${ }^{3}$, Ravindra P Nagendra ${ }^{4}$
}

\begin{abstract}
Objectives: This study was undertaken to compare the urine protein to creatinine ratio with 24-hour urine protein estimation in pregnancy complicated by hypertension and to establish the cutoff value of the urine protein to creatinine ratio for predicting significant 24-hour proteinuria.

Design: This is a comparative study and consists of a single group of 240 subjects.

Setting: This study was conducted in the Department of Obstetrics and Gynecology in collaboration with the Department of Biochemistry, JIPMER, Puducherry, India, from February 2011 to January 2013.

Population: The subjects included 240 pregnant women admitted after 20 weeks of gestation to the Jawaharlal Institute of Postgraduate Medical Education and Research (JIPMER) Hospital with hypertension ( $\geq 140 / 90 \mathrm{~mm} \mathrm{Hg}$ ). Patients with known cases of renal diseases, diabetes, and urinary tract infection were excluded.

Materials and methods: A first voided morning sample was obtained for urine protein and creatinine estimation, and urine culture. Subsequent urine samples were collected for the 24-hour urine protein estimation.

Main outcome measures: The spot urine protein to creatinine ratio and 24-hour urine protein were significantly correlated $(r=0.98 ; p<0.0001)$. The cutoff value for the protein to creatinine ratio as an indicator of protein excretion $\geq 300 \mathrm{mg} /$ day was 0.285 . The sensitivity and specificity were $100 \%$ and $99.02 \%$, respectively. The positive and negative predictive values were $100 \%$ and $99 \%$, respectively.

Results: The cutoff value for the protein to creatinine ratio as an indicator of protein excretion $\geq 300 \mathrm{mg} /$ day was 0.285 with significant correlation. Conclusion: The spot urine protein to creatinine ratio is valuable for clinical purposes.

Keywords: Hypertension in pregnancy, Protein to creatinine ratio, Proteinuria in pregnancy.

Journal of South Asian Federation of Obstetrics and Gynaecology (2019): 10.5005/jp-journals-10006-1695
\end{abstract}

\section{INTRODUCTION}

Hypertensive disorders of pregnancy complicate up to $10 \%$ of pregnancies and remain a major cause of maternal morbidity and mortality. ${ }^{1}$ Antenatal care involves a screening program, with the measurement of blood pressure and proteinuria performed more frequently toward term, and this information is used to detect hypertensive disorders of pregnancy.

Preeclampsia is a multisystem disorder of an unknown etiology, and it is characterized by the development of hypertension (140/90 $\mathrm{mm} \mathrm{Hg}$ or higher) with proteinuria after 20 weeks of pregnancy in previously normotensive and nonproteinuric patients. ${ }^{1}$ Proteinuria is defined as the presence of $300 \mathrm{mg}$ or more of protein in a 24 -hour urine specimen. ${ }^{2}$ The gold standard 24 -hour urine collection method for protein estimation is not without errors, and the most obvious error is variable and incomplete collection. This test is inconvenient and is associated with a delay in laboratory analysis and availability of results. Lack of storage facilities, staff inadequacy, and transportation also add to the difficulty. In some cases, delivery may occur before completion of 24-hour urine collection, and the patient often requires hospital admission to complete the test.

Estimation of the urine protein to creatinine ratio has shown promising results and correlates well with the 24-hour protein excretion. ${ }^{3-5}$ Therefore, it may be used as an alternative to 24 -hour urine protein excretion measurement.
${ }^{1}$ Department of Obstetrics and Gynecology, Gadag Institute of Medical Sciences, Gadag, Karnataka, India

${ }^{2}$ Department of Obstetrics and Gynecology, Jawaharlal Institute of Postgraduate Medical Education and Research, Puducherry, India

${ }^{3}$ Department of Pathology, BLDE (Deemed to be University), Vijayapura, Karnataka, India

${ }^{4}$ Department of Physiology, Gadag Institute of Medical Sciences, Gadag, Karnataka, India

Corresponding Author: Hanumant V Nipanal, Department of Obstetrics and Gynecology, Gadag Institute of Medical Sciences, Gadag, Karnataka, India, Phone: +919448001054, e-mail: hanumant.1210@ rediffmail.com

How to cite this article: Nipanal HV, Maurry DK, Reddy SS, et al. Correlation of the Protein to Creatinine Ratio with the 24-hour Urine Protein Level in Pregnancy Complicated by Hypertension. J South Asian Feder Obst Gynae 2019;11(4):235-238.

Source of support: Nil

Conflict of interest: None

\section{Aims and Objectives}

- To compare the urine protein to creatinine ratio with 24-hour urine protein estimation in pregnancy complicated by hypertension.

(c) The Author(s). 2019 Open Access This article is distributed under the terms of the Creative Commons Attribution 4.0 International License (https://creativecommons. org/licenses/by-nc/4.0/), which permits unrestricted use, distribution, and non-commercial reproduction in any medium, provided you give appropriate credit to the original author(s) and the source, provide a link to the Creative Commons license, and indicate if changes were made. The Creative Commons Public Domain Dedication waiver (http://creativecommons.org/publicdomain/zero/1.0/) applies to the data made available in this article, unless otherwise stated. 
- To establish the cutoff value of the urine protein to creatinine ratio for predicting significant 24 -hour proteinuria.

\section{Materials and Methods}

This study was conducted in the Department of Obstetrics and Gynecology and in collaboration with the Department of Biochemistry, JIPMER, Puducherry, India. This study was approved by the JIPMER Research Committee and Institute Ethics Committee on January 13, 2011 (IEC No. 2011/1/1 and dated 24/02/2011).

This is a comparative study and consists of a single group of 240 subjects. The sample size was calculated using the standard formula for estimating the sensitivity of a new test. The sample size was estimated by assuming a sensitivity of the spot urine protein to creatinine ratio for true proteinuria of more than or equal to $300 \mathrm{mg} /$ day as $95 \%$, with a $5 \%$ of level of significance and $4 \%$ desired precision.

\section{Inclusion Criteria}

Pregnant women hospitalized after 20 weeks of gestation with hypertension of $140 / 90 \mathrm{~mm} \mathrm{Hg}$ or higher on two occasions, at least 6 hours apart, were included in the study.

\section{Exclusion Criteria}

Patients with known renal disease, diabetes, and urinary tract infections were excluded from the study.

We studied the demographic profile, gestational age, blood pressure, urine protein to creatinine ratio, and 24-hour urine protein estimation of each patient. The procedure was explained, and consent was obtained from each patient. A first voided morning urine sample was obtained for urine protein and creatinine estimation, and urine culture. Subsequent urine samples were collected for 24 hours, including a next-day first morning voided sample, which was obtained for the 24-hour urine protein estimation.

Urine protein estimation was performed by the colorimetric method. Urine-creatinine estimation was performed by the modified Jaffe's method using a standard autoanalyzer. The sensitivity, specificity, and positive predictive and negative predictive values were determined for different protein to creatinine ratios. Receiver operating characteristic (ROC) curves were used for comparisons; values of greater than or equal to $300 \mathrm{mg} /$ day were considered true positive for proteinuria, and values of less than $300 \mathrm{mg} /$ day were considered true negative for proteinuria.

\section{Results}

A total of 240 subjects were recruited for the present study. Among them, 27 delivered before collection of the 24-hour urine sample. The 24-hour urine collection was incomplete for 23 subjects. Seven subjects exhibited no continuity between the spot urine collection and 24-hour urine collection, and seven subjects had a urinary tract infection. Thus, 64 subjects were excluded from the study. Therefore, 176 subjects were studied and followed up to 6 weeks postnatally, and among them, 7 had chronic hypertension. Ultimately, 169 subjects were included in the study.

The ages of subjects ranged from 18 years to 39 years, with the majority, 131 (87.51\%) subjects, in the age group of 21-30 years. The mean age was 25.09 years. Of the 169 subjects, 65 (39\%) had gestational hypertension, 100 (59\%) had preeclampsia, and 4 (2\%) had eclampsia. The preeclampsia group included subjects with mild preeclampsia, severe preeclampsia, and imminent eclampsia.
The subjects included 90 (53.25\%) primigravidas and 79 (46.75\%) multigravidas. The incidence of hypertensive disorders of pregnancy was similar in the primigravidas and multigravidas. Of the 169 subjects, the majority, 88 (52.07\%) subjects, were between 32 weeks and 37 weeks of gestation. A maximum number of subjects in the gestational hypertension $(33,50.77 \%)$, preeclampsia $(53,31.36 \%)$, and eclampsia $(2,50 \%)$ groups were also in the gestational age group of 32-37 weeks.

In $61.54 \%$ of the gestational hypertension group, $76 \%$ of the preeclampsia patients, and all 4 eclampsia patients, the blood urea levels were $>15 \mathrm{mg} / \mathrm{dL}$. In $4.62 \%$ of the subjects with gestational hypertension, $16 \%$ of those with preeclampsia and all patients with eclampsia had serum creatinine levels $<0.8 \mathrm{mg} / \mathrm{dL}$. A bilirubin level of $1.2 \mathrm{mg} / \mathrm{dL}$ was noted in one case. The incidence of anemia was $57.98 \%$. Three subjects had an aspartate aminotransferase (AST) level $>70$, and six subjects had an alanine transaminase (ALT) level $>70$. One subject in the preeclampsia group had a platelet level of $<1,00,000 / \mathrm{mm}^{3}$ Abnormalities were found on examination of the fundus in 13 subjects. Six of these subjects had grade I hypertensive retinopathy, and seven had grade II hypertensive retinopathy, while none had papilledema.

One subject had a body mass index (BMI) of $<18$, but the majority, 108 (63.91\%) subjects, had BMI values between 25 and 29.99. Nine subjects had a BMI $>35$. Eleven subjects had a history of hypertension during a previous pregnancy. A total of 143 subjects required antihypertensive medications to control their blood pressure. Twenty subjects received antepartum steroids, and 22 subjects received magnesium sulfate $\left(\mathrm{MgSO}_{4}\right)$.

Labor was induced in 128 subjects by various acceptable methods. Of the 169 subjects, 99 (59\%) had term deliveries, and 70 (41\%) had preterm deliveries. The subjects included 152 singleton pregnancies, while 15 had twins and 2 had triplets. One subject had a single fetal demise. Of the 191 babies from the 169 pregnancies, $132(69.11 \%)$ had a low birth weight of $<2500 \mathrm{~g}$. Forty-six $(25.14 \%)$ newborns were transferred to the neonatal intensive care unit. Nine $(4.92 \%)$ cases of intrauterine fetal death and nine $(4.92 \%)$ still births occurred. Furthermore, nine newborns expired in the neonatal intensive care unit. The incidence of prematurity was $41 \%$, while the incidence of intrauterine growth retardation was $15.38 \%$.

In our study, 102 (59\%) subjects had a protein excretion level of $<300 \mathrm{mg} /$ day, while 67 (40\%) had significant proteinuria $(\geq 300$ $\mathrm{mg} /$ day). A total of $52.24 \%$ of the proteinuria group had preterm deliveries, whereas $46.08 \%$ of the nonsignificant proteinuria group had preterm deliveries. The incidence of low birth weight $(<2,500 \mathrm{~g})$ was $61.53 \%$ in the proteinuria group. Of the 80 babies born to subject with significant proteinuria, 4 (5\%) exhibited intrauterine fetal death/still birth, while 20 (25\%) babies were transferred to the neonatal intensive care unit. Furthermore, three babies died in the neonatal intensive care unit.

During postnatal follow-up, 130 (76.92\%) subjects had their blood pressure normalized in $<48$ hours duration, and 37 (21.89\%) subjects had normal blood pressure on first follow-up during the 2nd postnatal week. Two subjects had a normal blood pressure on follow-up during the 4 th postnatal week. The blood pressure was persistently high beyond the 12 weeks of follow-up for 7 subjects, and they were considered to have chronic hypertension and were excluded from the study.

An excellent correlation exists between the spot urine protein to creatinine ratio $(\mathrm{mg} / \mathrm{mg})$ and the 24 -hour urine protein (mg/mg) (Fig. 1). 


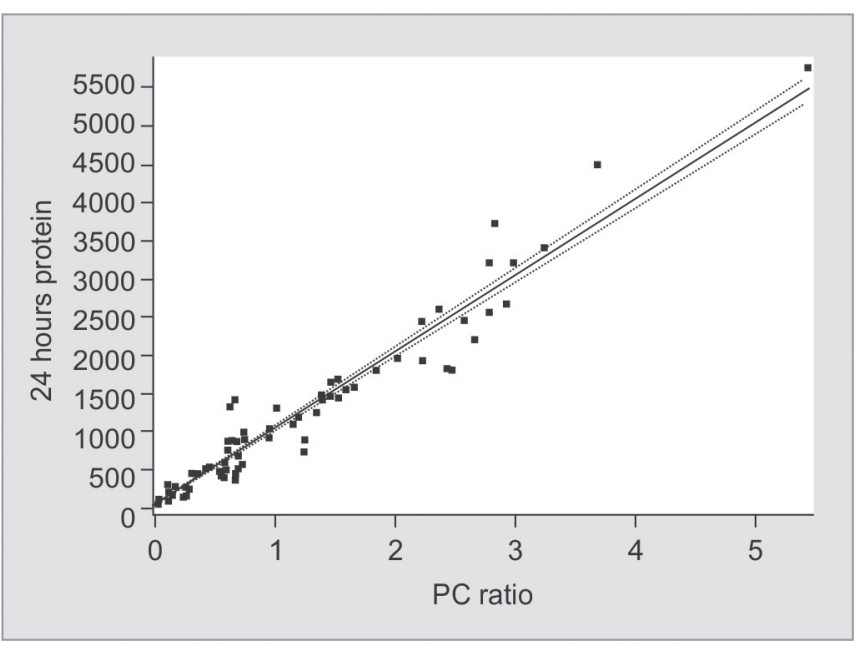

Fig. 1: Correlation of spot urine protein to creatinine $(\mathrm{PC})$ ratio $(\mathrm{mg} / \mathrm{mg})$ and the 24 -hour urine protein $(\mathrm{mg} / \mathrm{mg}$ )

The area under the ROC curve is 0.999 ( $95 \%$ confidence interval). The best cutoff value for the protein to creatinine ratio for detecting significant proteinuria according to the ROC curve is 0.285 , with $100 \%$ sensitivity, $99.02 \%$ specificity, $100 \%$ positive predictive value, and $99 \%$ negative predictive value (Fig. 2).

\section{Discussion}

This study consisting of 169 subjects revealed a $p$ value of $<0.0001$ (two-tailed), which is considered extremely significant, and an excellent correlation coefficient $(r=0.9778)$, with a $95 \%$ confidence interval of $0.9700-0.9836$, for the spot urine protein to creatinine ratio $(\mathrm{mg} / \mathrm{mg})$, and 24 -hour urine protein ( $\mathrm{mg} /$ day) calculated by Pearson's method (Table 1).

The coefficient of determination ( $r$ squared) is 0.9561 . Table 2 shows the results of similar studies compared to those of the present study in terms of the correlation coefficient for the protein to creatinine ratio with 24 -hour protein.

Receiver operating characteristic curves for the spot urine protein to creatinine ratio show an area under the ROC curve of 0.999 (95\% confidence interval) (Fig. 2).

The cutoff value of 0.285 results in a sensitivity of $100 \%$, a specificity of $99.02 \%$, a positive predictive value of $99 \%$, and a negative predictive value of $100 \%$, with a $67 \%$ likelihood ratio.

In the study by Leanos-Miranda et al., ${ }^{12}$ the cutoff value was $\geq 0.3$ with a $98.2 \%$ sensitivity, $98.8 \%$ specificity, $97.2 \%$ positive predictive value, and $99.2 \%$ negative predictive value. A study by Ramos et al. ${ }^{13}$ showed a cutoff value of $0.5^{14}$ with a sensitivity of $96 \%$, a specificity of $96 \%$, a positive predictive value of $96 \%$, and a negative predictive value of $96 \%$, whereas in the study by Rodriguez-Thompson and Lieberman, $^{15}$ the best cutoff value of $\geq 0.19$ yielded a sensitivity of $90 \%$ and a specificity of $70 \%$. In the study by Yamasmit et al., ${ }^{16}$

Table 1: Correlation coefficient between the spot urine protein to creatinine ratio $(\mathrm{mg} / \mathrm{mg})$ and the 24 -hour urine protein $(\mathrm{mg} /$ day) calculated by Pearson's method

\begin{tabular}{lllll}
\hline $\begin{array}{l}\text { Number of } \\
\text { subjects }\end{array}$ & $\begin{array}{l}p \text { value } \\
\text { (two tailed) }\end{array}$ & $\begin{array}{l}95 \% \\
\text { confidence } \\
\text { interval }\end{array}$ & $\begin{array}{l}\text { Correlation } \\
\text { coefficient }(r)\end{array}$ & $\begin{array}{l}\text { Coefficient } \\
\text { of determi- } \\
\text { nation }\left(r^{2}\right)\end{array}$ \\
\hline 169 & $<0.0009$ & $0.9700-$ & 0.9778 & 0.9561 \\
& & 0.9836 & & \\
\hline
\end{tabular}

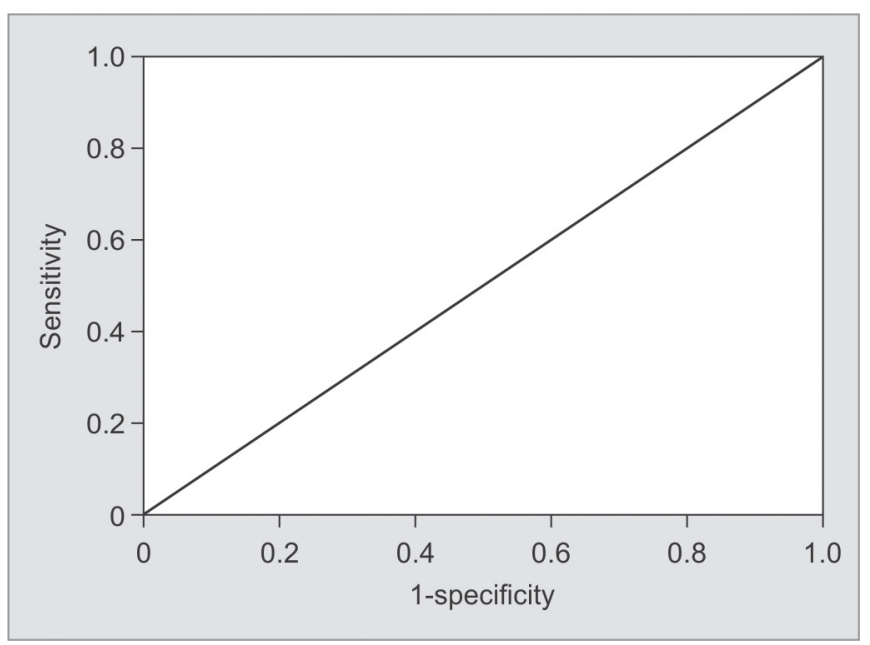

Fig. 2: Receiver operating characteristic curves for the spot urine protein to creatinine ratio show an area under the ROC curve of 0.999 (95\% confidence interval)

Table 2: Comparison of present study with previous studies

\begin{tabular}{lll}
\hline Studies & Correlation coefficient & p values \\
\hline Ginsberg et al. $^{6}$ & 0.93 & $<0.001$ \\
Neithardt et al. $^{7}$ & 0.93 & $<0.001$ \\
Robert et al. $^{8}$ & 0.94 & $<0.001$ \\
Boler et al. $^{9}$ & 0.99 & $<0.001$ \\
Saudan et al. $^{3}$ & 0.93 & $<0.001$ \\
Young et al. $^{10}$ & 0.80 & $<0.001$ \\
Jaschevatzky et al. $^{11}$ & 0.92 & $<0.001$ \\
Present study & 0.98 & $<0.001$ \\
\hline
\end{tabular}

a cutoff value of 0.19 demonstrated a sensitivity of $100 \%$ and a specificity of $53.8 \%$.

\section{Conclusion}

The level of urinary protein excretion has considerable clinical implications for the course of pregnancy and the perinatal and maternal outcomes. Therefore, early detection of even minor degrees of proteinuria is important.

Dipstick analysis as a screening procedure for proteinuria lacks reliability and has a high rate of false-positives. For years, the 24-hour urine collection method has been the gold standard for the quantitation of proteinuria in the management of women with preeclampsia. However, this method is cumbersome, is subject to collection errors, requires good patient compliance, and results in a delayed diagnosis. The value of the protein to creatinine ratio in a single urine sample is potentially more accurate because it avoids collection errors and may yield more physiologically relevant information.

Quantitating proteinuria in a random sample has been found to be more convenient and acceptable to the patient than a 24-hour urine collection, which often requires hospitalization. Since preeclampsia is a progressive disease, repeated laboratory examinations to quantitate proteinuria are required. The repeated collection of 24-hour urine samples is not practical. Therefore, the protein to creatinine ratio is a superior diagnostic tool for predicting significant proteinuria.

The cutoff value for the spot urine protein to creatinine ratio is $0.285 \mathrm{mg}$ protein $/ \mathrm{mg}$ creatinine. A level below this is not associated 
with significant proteinuria, and further testing is unnecessary. This method for the quantitation of proteinuria, when properly interpreted, can provide valuable information for clinical purposes and is a satisfactory substitute for 24 -hour protein estimation. It is useful in the outpatient setting to predict clinically significant proteinuria without causing an inconvenience to women, and it avoids unnecessary hospitalization. The spot urine protein to creatinine ratio is valuable for clinical purposes and is a satisfactory substitute for 24-hour protein estimation.

\section{LIMITATIONS}

This study was limited to hospitalized, nonambulatory patients. Since protein excretion is affected by postural changes, the ambulatory status of the subjects (i.e., patients that are allowed to stand vs those confined to a supine position) may be a confounding factor in the quantitation of proteinuria.

\section{Author Contributions}

Dr Hanumant V Nipanal: Subject recruitment, data collection, and manuscript preparation. Dr Dilip K Maurya: Conceived idea and Protocol preparation. Dr Susmitha S Reddy: Manuscript preparation. Dr Ravindra P Nagendra: Statistical analysis.

\section{Detalls of Ethics Approval}

This study with reference number IEC No. SEC/2011/1/1 and dated 24/02/2011 has been approved by Jawaharlal Institute of Postgraduate Medical Education and Research (JIPMER), Puducherry, India-605006, Research Committee and Institute Ethics Subcommittee (human studies) on 13th January 2011 on 24-02-2011.

\section{ACKNOWLedgments}

The author would like to thank professor Dilip Kumar Mayurya for his expert advice and encouragement through this difficult project as a guide as well as professor PH Ananthanarayanan for his brilliance in laboratory as co-guide.

\section{References}

1. Gifford RW, Cunningham G, Green LA, et al. Report of the national high blood pressure education program working group on high blood pressure in pregnancy. Am J Obstet Gynecol 2000;183(1):S1-S22. DOI: 10.1067/mob.2000.107928.

2. Saudan P, Brown MA, Buddle ML, et al. Does gestational hypertension become pre-eclampsia? Br J Obstet Gynaecol 1998;105(11):1177-1184. DOI: 10.1111/j.1471-0528.1998.tb09971.x.
3. Saudan PJ, Brown MA, Farrell T, et al. Improved methods of assessing proteinuria in hypertensive pregnancy. Br J Obstet Gynaecol 1997;104(10):1159-1164. DOI: 10.1111/j.1471-0528.1997. tb10940.x.

4. Waugh JJ, Bell SC, Kilby MD, et al. Optimal bedside urinalysis for the detection of proteinuria in hypertensive pregnancy: a study of diagnostic accuracy. BJOG 2005;112(4):412-417. DOI: 10.1111/j.14710528.2004.00455.x.

5. Kyle PM, Fielder JN, Pullar B, et al. Comparison of methods to identify significant proteinuria in pregnancy in the outpatient setting. BJOG 2008;115(4):523-527. DOI: 10.1111/j.1471-0528.2007.01621.x.

6. Ginsberg JM, Chang BS, Matarese RA, et al. Use of single voided urine samples to estimate quantitative proteinuria. $\mathrm{N}$ Engl J Med 1983;309(25):1543-1546. DOI: 10.1056/NEJM198312223092503.

7. Neithardt AB, Dooley SL, Borensztajn J. Prediction of 24-hour protein excretion in pregnancy with a single voided urine proteinto-creatinine ratio. Am J Obstet Gynecol 2002;186(5):883-886. DOI: 10.1067/mob.2002.123055.

8. Robert M, Sepandj F, Liston RM, et al. Random protein-creatinine ratio for the quantitation of proteinuria in pregnancy. Obstet Gynecol 1997;90(6):893-895. DOI: 10.1016/S0029-7844(97)00536-X.

9. Boler L, Zbella EA, Gleicher N. Quantitation of proteinuria in pregnancy by the use of single voided urine samples. Obstet Gynecol 1987;70(1):99-100.

10. Young RA, Buchanan RJ, Kinch RA. Use of the protein/creatinine ratio of a single voided urine specimen in the evaluation of suspected pregnancy-induced hypertension. J Fam Pract 1996;42(4): 385-389.

11. Jaschevatzky OE, Rosenberg RP, Shalit A, et al. Protein/creatinine ratio in random urine specimens for quantitation of proteinuria in preeclampsia. Obstet Gynecol 1990;75(4):604-606.

12. Leanos-Miranda A, Marquez-Acosta J, Romero-Arauz F, et al. Protein:creatinine ratio in random urine samples is a reliable marker of increased 24-hour protein excretion in hospitalized women with hypertensive disorders of pregnancy. Clin Chem 2007;53(9): 1623-1628. DOI: 10.1373/clinchem.2007.089334.

13. Ramos JG, Martins-Costa SH, Mathias MM, et al. Urinary protein/ creatinine ratio in hypertensive pregnant women. Hypertens Pregnancy 1999;18(3):209-218. DOI: 10.3109/10641959909016194.

14. James PR, Nelson-Piercy C. Management of hypertension before, during, and after pregnancy. Heart 2004;90(12):1499-1504. DOI: 10.1136/hrt.2004.035444.

15. Rodriguez-Thompson $D$, Lieberman ES. Use of a random urinary protein-to-creatinine ratio for the diagnosis of significant proteinuria during pregnancy. Am J Obstet Gynecol 2001;185(4):808-811. DOI: 10.1067/mob.2001.117349.

16. Yamasmit W, Chaithongwongwatthana $S$, Charoenvidhya $D$, et al. Random urinary protein-to-creatinine ratio for prediction of significant proteinuria in women with preeclampsia. J Matern Fetal Neonatal Med 2004;16(5):275-279. DOI: 10.1080/jmf.16.5. 275.279. 